\title{
Ulcerative Colitis and Lung
}

\author{
Nilgün Yilmaz Demirci \\ Ataturk Chest Disease and Chest Surgery Training and Research Hospital, \\ Pulmonary Medicine Department, Ankara \\ Turkey
}

\section{Introduction}

Inflammatory bowel disease (IBD) refers to a group of conditions characterised by inflammation in the intestinal tract. Crohn disease (CD) and ulcerative colitis (UC) account for the majority of these conditions. Since these disorders have both distinct and overlapping pathologic and clinical characteristics in this part both diseases are discussed together.

Multiple studies have evaluated the epidemiology of IBD in various geographic regions. In North America, incidence rates range from 2.2 to 14.3 cases per 100,000 person-years for UC and 3.1 to 14.6 cases per 100,000 person-year for CD ([1]). Prevalence rates range from 37 to 246 per 100,000 persons for UC and from 26 to 201 cases per 100,000 for CD. The incidence and prevalence of CD and UC appear to be lower in Asia, Japan, and South America ([2]). IBD can present at any age, although the peak incidence occurs between the ages of 15 and 30 years. A second peak in the incidence of CD occurs between the ages of 50 to 80 . There is no gender specificity $([3,4])$.

While numerous environmental factors have been hypothesized to affect risk of a phenotype of IBD, only a few associations have been reproducible and implicated in the pathogenesis of IBD. These factors as smoking, appendectomy, infection, oral contraceptives, isotretinoin are more likely to contribute to disease in susceptible subjects ([2]).

The strongest evidence for an environmental factor has been the association between cigarette smoking and IBD. Several studies have demonstrated a negative correlation between smoking and $\mathrm{UC}$, but a positive correlation between smoking and $\mathrm{CD}$ recurrence $([5,6,7,8,9,10])$.

A variety of conditions arise outside of the gastrointestinal tract that are associated with IBD; these are termed extraintestinal manifestations of IBD which are very common: dermatological manifestations, erythema nodosum and pyoderma gangrenosum; ocular manifestations, uveitis and episcleritis; hepatobiliary manifestations, primary sclerosing cholangitis and autoimmune hepatitis; musculoskeletal manifestations, peripheral arthritis and axial arthropathy. In contrast, pulmonary involvement is rare ([11]).

Involvement of the respiratory tract, although relatively rare, is increasingly recognized in patients with IBD since the original report in 1976 of six patients with unexplained chronic purulent sputum production ([12]). These abnormalities are generally related to the underlying bowel disease, although interstitial lung disease can also be induced by 
administration of certain drugs, including sulfasalazine, 5-aminosalicylic acid, methotrexate, azathioprine and infliximab $([13,14,15,16,17])$.

\section{Demographic considerations}

Respiratory complications have been more commonly described with ulcerative colitis than with Crohn's disease. In one study of 33 patients, for example, 27 had ulcerative colitis and six had Crohn's disease. The three patterns of presentation (airway disease, parenchymal disease, and serositis) had somewhat different characteristics in terms of sex preponderance and activity of the bowel disease ([12]). There was a female preponderance of almost 2:1 for all bronchopulmonary complications as a whole and 3 to $4: 1$ for bronchial complications. In contrast, serositis occurred with roughly equal frequency in men and women.

Bronchopulmonary complications followed the onset of inflammatory bowel disease in 80 to 85 percent of patients, preceded bowel disease in 10 to 15 percent, and developed concomitantly in 5 to 10 percent ([12]).

Respiratory involvement in IBD is disclosed with some pathophysiological mechanisms: both the colonic and respiratory epithelia share embryonic origin from the primitive foregut, and both types of epithelial cells include goblet cells and submucosal glands; and the lungs and gastrointestinal tract contain submucosal lymphoid tissue and play crucial roles in host mucosal defense. The similarity in the mucosal immune system causes the same pathogenetic changes. The aberrations in both innate and acquired immunity that are involved in the pathogenesis of IBD are complex and still incompletely understood ( [11, 17]). In this context it has been speculated that colonic surgery may promote the onset of respirtory, as suggested by case histories ([12]).

The patterns of involvement in IBD are $([11,17])$ :

- Upper airway: glottic/subglottic stenosis, tracheal inflammation and stenosis;

- Bronchi: chronic bronchitis, bronchiectasis, and chronic bronchial suppuration;

- Small airways: bronchiolitis obliterans, bronchiolitis, and diffuse pan-bronchiolitis;

- Lung parenchyma: bronchiolitis obliterans-organizing pneumonia, nonspecific interstitial pneumonia, granulomatous interstitial lung disease, desquamative interstitial pneumonitis, pulmonary infiltrates and eosinophilia, and sterile necrobiotic nodules;

- $\quad$ Sarcoidosis, a1 antitrypsin deficiency;

- Pulmonary vascular disease; Wegener's granulomatosis, Churg-Strauss syndrome, microscopic polyangiitis, and pulmonary vasculitis, venous thromboembolism; and Serositis: pleural and pericardial manifestations.

\section{Respiratory symptoms}

The prevalence of respiratory symptoms in IBD patients without pulmonary pathology has been examined in a number of small studies. Among 44 randomly selected IBD patients, Douglas et al ([18]) found that $48 \%$ had unspecified respiratory symptoms. Songur et al ([19]) found that 16 of 36 IBD patients (44\%) in a gastroenterology clinic had symptoms of wheeze, cough, sputum production, or breathlessness. Finally, Ceyhan and others ([20]) found 15 of 30 consecutively surveyed IBD patients had symptoms of dyspnea, cough, sputum, or wheeze for $>1$ month. These investigations, while limited in scope, suggest that 
patients with IBD have pulmonary symptoms with greater frequency than the general population.

\section{Radiologic findings}

Chest radiography is often normal in patients with respiratory symptoms and IBD. Bronchiectasis is the classic pulmonary manifestation of IBD, and is noted in $66 \%$ of cases of IBD that involve the large airways ( Figure 1)([17]).

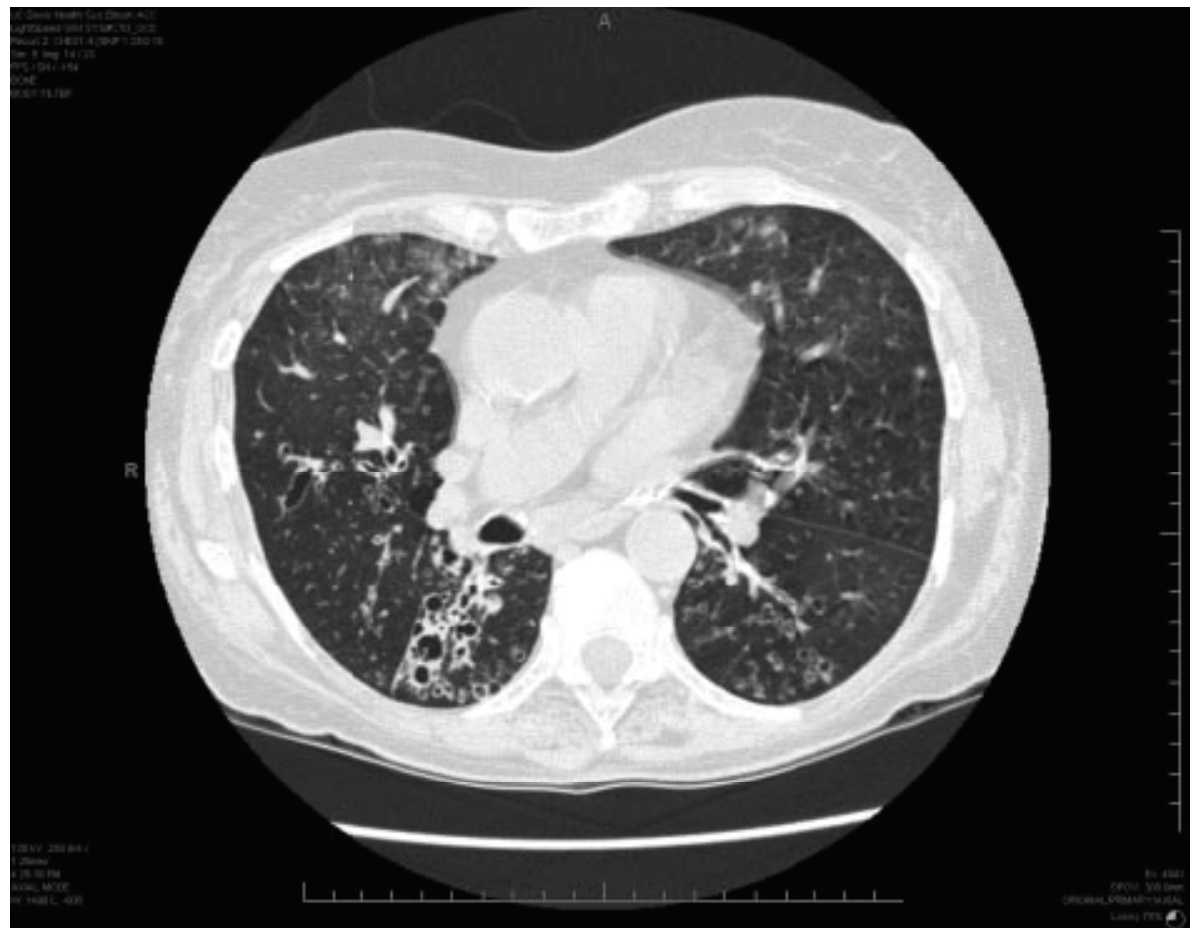

Fig. 1. CT showing bronchiectasis and inflammatory nodules in a 72-year-old woman with UC ([17])

Mahadeva et al ([21]) have found bronchiectasis in 13 of 17 patients with IBD, in whom sputum production was present in 10. In contrast, bronchiectasis was identified in only two patients in the present study. In the study of Yilmaz et al, the most frequent finding on HRCT was peribronchial thickness. The most common respiratory association of IBD is inflammation of the airways. Biopsy shows either severe nonspecific chronic inflammation or non-caseating tuberculoid granulomas. They concluded that these appearances have been associated with those in the bowel, and it is possible that the gut and the lung are both affected because they share common antigens. This inflammation is perceived on HRCT as an increase in bronchial wall thickness or an increase in diameter of pulmonary artery branches. In these patients, bronchial dilatation is commonly present and results from traction by fibrous tissue on the bronchial walls and results in bronchiectasis. Consequently, 
they suggested that peribronchial thickness might reflect inflammation, which usually responds well to steroids. They concluded that in this way, bronchiectasis can be prevented. And so this finding suggests a direct pathogenic link to IBD as well ([11]).

\section{Pulmonary function}

A number of investigations have focused on results of pulmonary function testing (PFT) among patients with IBD. Case-control studies designed to investigate the hypothesis that IBD is associated with abnormal pulmonary function have been limited by low numbers of patients and poor choice of control subjects. A number of reports have demonstrated a decrease in diffusion capacity of the lung for carbon monoxide (DLco). Two studies by Tzanakis et al $([22,23])$ have shown that DLco was significantly lower among IBD patients with active GI disease than those in remission. In the same study an increased prevalence of small airway dysfunction among IBD patients have shown. Marvisi et al ([24]) reported a similar finding in a smaller cohort with UC. This suggests that degree of GI inflammation may correlate with the severity of lung disease in these patients.

Other reports have employed less conventional measures of airflow obstruction to identify subclinical pulmonary disease. Patients with active UC had increased airway obstruction compared with patients with inactive UC. Pasquis et al ([25]) found an increase in functional residual capacity among a small number of patients with CD. Two groups, Mansi and colleagues ([26]) and Louis et al $([27,28])$ have documented increased bronchial response to methacholine, a measure of airway hyperactivity, among patients with both UC and CD, but this was not confirmed in another study. Ceyhan et al revealed that the prevalence of allergic symptoms, positive skin tests, and functional abnormalities was significantly higher in patients with IBD. ([20]).

Nitric oxide (NO) is a mediator of inflammation in a number of pathological processes. It is elevated in exhaled air (eNO) from asthmatic patients compared with healthy volunteers, and also in aspirated colonic gas from patients with Crohn's disease. Koek et al studied 31 patients with Crohn's disease and 24 with ulcerative colitis. The authors found that eNO was elevated in active IBD, and in addition, observed a negative correlation between spirometry values and disease activity in patients with Crohn's disease ([29]). Ozyilmaz et al evaluated the value of fractional concentration of exhaled $\mathrm{NO}$ (FeNO) level for the diagnosis of pulmonary involvement due to IBD and to investigate any correlation between FeNO level and disease activity. They concluded that an increased FeNO level may be used for identifying patients with IBD who need further pulmonary evaluation ([30]) .

\section{Patterns of involvement}

Upper airway: Glottic/subglottic stenosis, tracheal inflammation and stenosis; are associated with inflammation, friability, and pseudotumors in the trachea which results in airway narrowing. The primary symptoms are cough and hoarseness, although some patients develop upper airway obstruction with resulting stridor and severe dyspnea ([20]). In endoscopic examination glottic/subglottic oedema, inflammation can be seen.

Airway inflammation: Chronic bronchitis, bronchiectasis, and chronic bronchial suppuration; inflammation of the trachea, bronchi, and bronchioles can occur in inflammatory bowel disease, with bronchial involvement being most common, accounting for $39 \%$ of all cases reviewed $([12,31,32,33])$. Patients with large airways disease may also 
have coincident nonthoracic extraintestinal manifestations, including microangiopathic hemolytic anemia, pyoderma gangrenosum, primary sclerosing cholangitis, episcleritis, and peripheral and axial arthritis. Bronchial involvement may be manifested as unexplained chronic bronchitis or as bronchiectasis. Bronchiectasis is the classic pulmonary manifestation of IBD, noted in $66 \%$ of instances of IBD involving the large airways ([17]). Patients can be asymptomatic or present with cough and variable amounts of mucopurulent sputum production. Cultures of bronchial secretions are typically unrevealing, and the symptoms are generally not responsive to antibiotics. Chest radiographs are frequently normal or show nonspecific changes resulting from bronchial wall thickening or bronchiectasis. High resolution chest CT scanning is more sensitive than plain chest radiographs, often demonstrating findings of bronchial wall thickening, dilated airways with thickened walls, or branched opacities suggestive of mucoid impaction $([34,35])$.

Interestingly, nine patients, mostly with UC, presented with or had a recrudescence of bronchiectasis within 1 year of colectomy. In one case, bronchiectasis presented within weeks of colectomy. This temporal link between colonic resection and onset or worsening of pulmonary disease has fueled speculation that colectomy may actually induce pulmonary disease in these patients ([12]). Alternatively, this phenomenon may be related to the discontinuation of immunosuppressive therapies after presumed surgical cure of the disease ([17]).

Small airway involvement: Bronchiolitis obliterans, bronchiolitis, and diffuse panbronchiolitis; can cause cough, variable sputum production, wheezing, and airflow obstruction. Small airway involvement in IBD tends to present at a younger age and at an earlier point in the disease course than abnormalities of the large airways. In contrast to other airway manifestations, diseases of the small airways more commonly occur before symptomatic GI disease (29\% of surveyed cases) ([17]). Pathologic findings include nonspecific inflammation, narrowing, and fibrosis of small airways; granulomatous bronchiolitis $(58.8 \%)$ has also been reported $([15,36])$. Small airway involvement can cause abnormalities in pulmonary function in patients with normal chest radiographs. In one series of 82 patients with IBD and normal plain chest radiographs, 47 (57 percent) had abnormal findings on complete pulmonary function tests ([16]). Most of these patients had findings consistent with restrictive lung disease. High resolution chest $\mathrm{CT}$ can demonstrate mosaic perfusion or tree-in-bud ([12]).

Pulmonary parenchymal disease: Bronchiolitis obliterans-organizing pneumonia(BOOP), nonspecific interstitial pneumonia, granulomatous interstitial lung disease, desquamative interstitial pneumonitis, pulmonary infiltrates and eosinophilia, and sterile necrobiotic nodules.

Several patterns of lung parenchymal involvement have now been described in inflammatory bowel disease, with bronchiolitis obliterans with organizing pneumonia and interstitial lung disease being most common $([12,13])$. UC is the underlying form of IBD in the majority of reported cases of IBD-associated parenchymal lung disease. Age of onset varies, and there is a slight female predominance. One study of 85 patients with ulcerative colitis and 47 patients with Crohn's disease found that diffusing capacity was significantly lower during exacerbations of bowel disease than when gastrointestinal disease was quiescent ([22]). No pulmonary symptoms were associated with these transient physiologic derangements. These results have been confirmed in other reports, suggesting that pulmonary inflammation commonly accompanies inflammation of the bowel ([24]).

BOOP presents in an acute or subacute fashion with variable combinations of fever, dyspnea, cough, and pleuritic chest pain ([12]). Chest radiographic findings range from 
patchy focal opacities to diffuse infiltrates, while CT scanning often demonstrates the opacities to be pleural-based and sometimes associated with air bronchograms (Figure 2) ([21]).

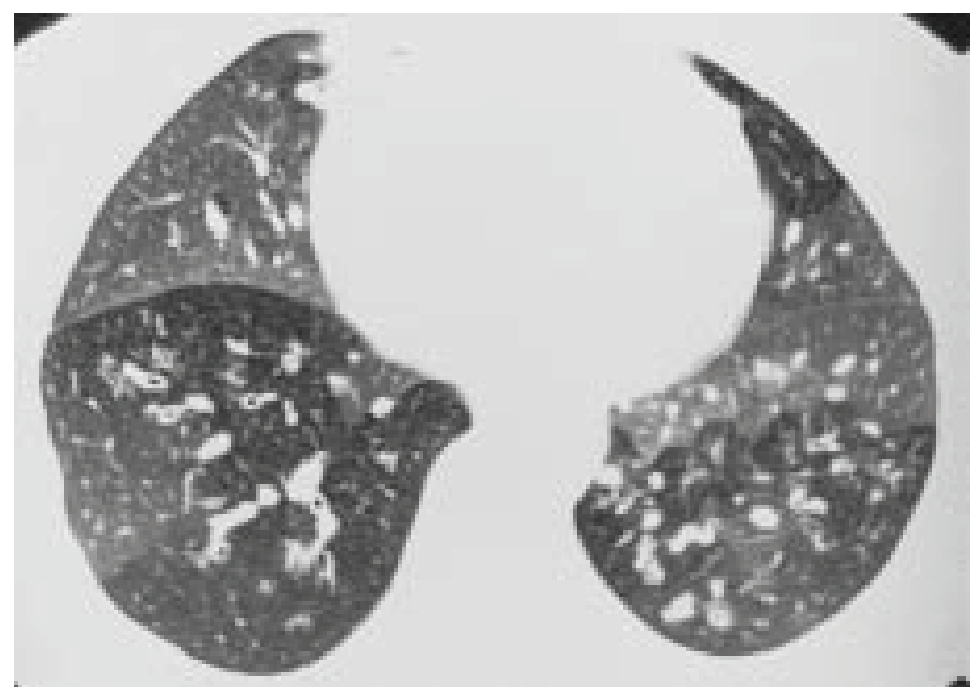

Fig. 2. High resolution computed tomography. On expiration, there is evidence of extensive air trapping in keeping with obliterative bronchiolitis ([21])

Sarcoidosis: IBD and sarcoidosis are usually considered to be distinct entities. However, the cumulative volume of case reports documenting coexistence of these two entities suggests a link between them. Fifty-three cases of IBD and concomitant sarcoidosis have been reported in the literature ([17]). The pathophysiologic basis of a relationship between IBD and sarcoidosis is unclear. Genetic susceptibility and derangements of cellular immunity play important roles in the development of both. Barr et al reported that human leukocyte antigen (HLA)-B8 and HLA-DR3 haplotypes were present in three of eight patients with UC and sarcoidosis, a higher proportion than expected ([37]). Papadopoulos et al reported a greater incidence of a variety of autoimmune diseases in patients with sarcoidosis, and suggested that HLA-linked genetic susceptibility (HLA-B8/DR3) predisposes sarcoidosis patients to a variety of autoimmune diseases ([38]). Finally, IBD and sarcoidosis share comparable dermatologic, ocular, and joint manifestations, further suggesting a pathogenic link. Nontuberculous Mycobacterium species have been postulated as an infectious cause of, and have been detected in tissues from patients with, both IBD and sarcoid ([39]). Elevated CD4:CD8 ratios on BAL, a characteristic but not diagnostic finding in sarcoidosis, have also been documented in patients with CD $([40,41])$.

$\mathbf{a}_{1}$ - antitrypsin deficiency: $\alpha_{1}$ - antitrypsin deficiency can lead to the development of pulmonary emphysema and hepatic dysfunction. In a study 10 patients, 7 with emphysema, who had concomitant $\mathrm{a}_{1}$ - antitrypsin deficiency and IBD have identified. Combined with the complex effects of smoking on the prevalence and course of UC and CD, this observation has lead the authors to propose that, as in the lung, imbalances in neutrophil elastase regulation exhibited in $\mathrm{a}_{1}$-antitrypsin deficiency may enhance potential local tissue damage in the gastroenterological tract from smoking ([42]). 
Intestinal manifestations of a pulmonary vasculitis such asWegener granulomatosis, ChurgStrauss syndrome, microscopic polyangiitis, and pulmonary vasculitis have been reported. Bloody diarrhea, abdominal pain, and intestinal perforation have been described in these patients. The symptoms can mimic IBD and make diagnosis difficult without biopsy ([15]).

Pulmonary infiltrates with eosinophilia (PIE syndrome); is a recognized complication of sulfasalazine, which is commonly used in the therapy of ulcerative colitis. There are also case reports of eosinophilic pneumonia in association with mesalamine therapy. However, this syndrome can occur in patients with inflammatory bowel disease who have no history of sulfasalazine use. Eosinophilia is frequently present in the peripheral blood, and chest radiographs often show peripheral infiltrates typical of chronic eosinophilic pneumonia ([2]). Necrobiotic nodules resemble radiographically the cavitating nodules that can be seen with either septic pulmonary emboli or Wegener's granulomatosis . Histologically, the nodules are composed of sterile aggregates of neutrophils with necrosis, findings that are similar to those of pyoderma gangrenosum, a cutaneous complication of inflammatory bowel disease ([43]).

Serositis: As a complication of inflammatory bowel disease, serositis involving intrathoracic structures has occurred in the form of pleural effusions, pericarditis, pleuropericarditis, and myopericarditis ([12]). The serosal fluid is exudative, with a cellular content generally composed primarily of neutrophils. In a single case in which pleural biopsy was reported, nonspecific inflammation without granulomas was found. The pericardium is uniquely involved in $45 \%$ of cases ([44]).

Pulmonary embolism: Venous thromboembolism (VTE) represents a relevant cause of morbidity and mortality among patients with IBD. Compared to non-IBD subjects, patients with IBD are at a 3- to 4-fold increased risk of VTE and are affected by VTE at a younger age $([45,46,47])$. The majority of thromboembolic events among IBD patients are VTE, manifested as either deep venous thrombosis or pulmonary embolism, but arterial thromboembolism and venous thrombosis at unusual sites have also been reported ([48]). The pathogenesis of increased thrombotic risk among patients with IBD is unclear. The prevalence of inherited prothrombotic disorders is no higher among patients with IBD than in the general population. While laboratory markers of activation of the coagulation system have been found in some patients with IBD, the significance of this finding is unclear. IBD patients often have acquired thrombosis risk factors in conjunction with their disease or its treatment, including immobility, surgery, and central venous catheters. However, up to one third of thrombotic events among IBD patients occur while their disease is quiescent, suggesting ongoing thrombotic risk unrelated to disease activity or therapy $([49,50,51])$. Active disease, fistulas, and abscesses are present in the majority of IBD patients at the time of the thromboembolic event. Furthermore, IBD patients are more often exposed to diseaserelated risk factors that may provoke VTE, including surgery, immobilization, dehydration, and central venous catheters $([47,48,52])$. Patients who present with the acute development of unexplained pulmonary symptoms, tachycardia, lower extremity swelling, and/or hypoxemia should be assessed for possible pulmonary embolism ([17]).

Drug-induced Complications: Patients with inflammatory bowel disease are often treated with sulfasalazine and 5-aminosalicylic acid (5-ASA), both of which can cause pulmonary disease ([14, 53, 54]). Methotrexate, infliximab, and azathioprine / 6-mercaptopurine are also used in selected patients, and can induce pulmonary toxicity.

Sulfasalazine: Pneumonitis, commonly seen in conjunction with fever and rash, is a recognized complication of sulfasalazine therapy. Nearly one-half of affected patients 
present with the clinical syndrome of pulmonary infiltrates with eosinophilia. The infiltrates are commonly in upper lobe (Figure 3) ([53]).

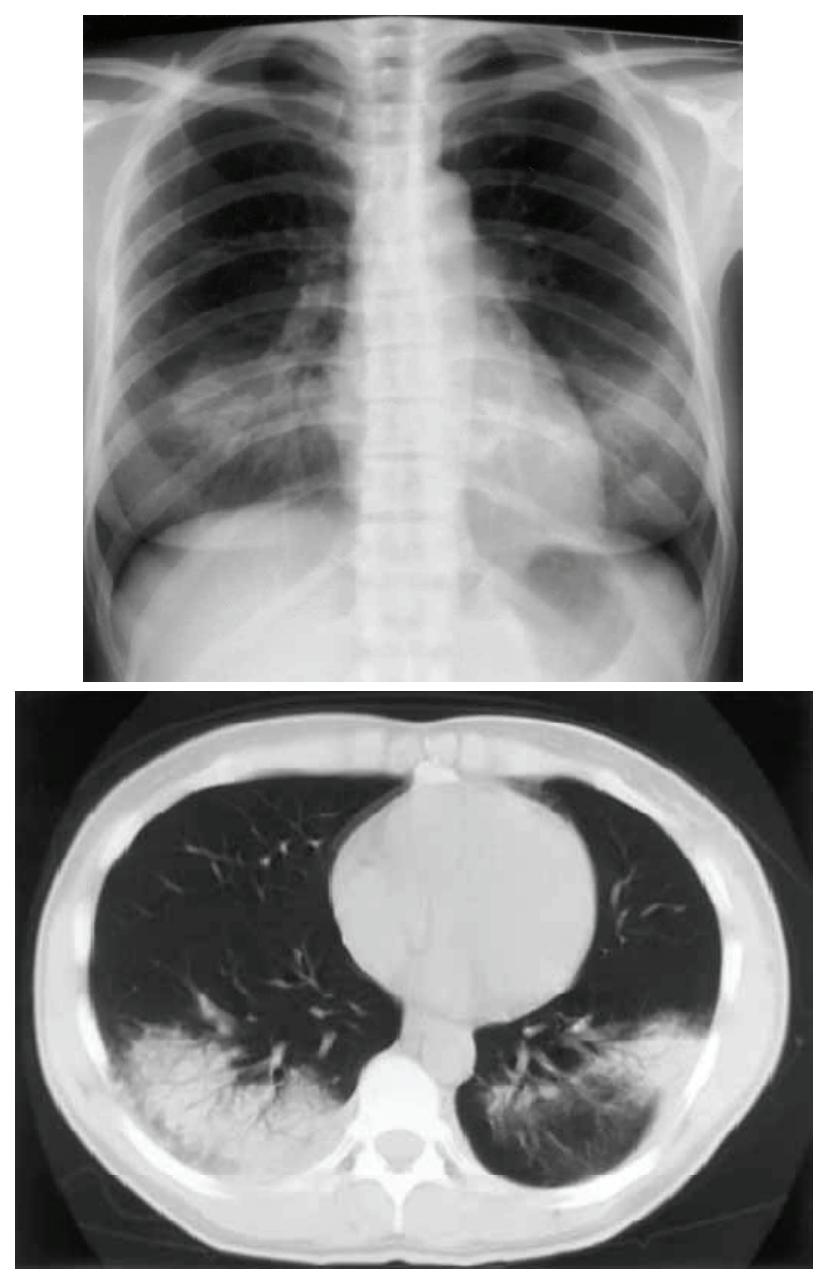

Fig. 3. Chest radiograph and computed tomography of the patient showing bilaterally interstitial infiltrates with air-bronchogram in both lower lung fields ([53])

Other pulmonary disorders have also been associated with sulphasalazine, including interstitial lung disease, bronchiolitis obliterans with organizing pneumonia, granulomatous lung disease, and rarely pleural effusion $([12,55])$.

Most reactions related to sulfasalazine or mesalamine are seen between 2-6 months of drug administration. The most common symptoms are dyspnea (76\%), fever $(68 \%)$, chest pain $(65 \%)$ and cough $(22 \%)$. Peripheral eosinophilia is found in almost half of the reported cases, diffusion capacity was decreased in a large percentage of patients and most had bilateral infiltrates or opacities on chest radiograph ([15]). A pulmonary picture consistent with Wegener's granulomatosis has also been attributed to sulfasalazine ([56]). 
In general, patients with sulphasalazine-induced pulmonary disease improve with drugwithdrawal; in one analysis, two of three patients who continued on the drug died ([52]).

5-aminosalicylic acid: Pulmonary toxicity attributable to 5-aminosalicylic acid (5-ASA or mesalamine) is less common than with sulfasalazine. Some affected patients have diffuse or basilar infiltrates, sometimes with eosinophilia or may develop bronchiolitis obliterans ([53]).

Methotrexate: Methotrexate is an analogue of the vitamin folic acid and inhibits cellular proliferation by inducing an acute intracellular deficiency of certain folate coenzymes. Serious toxicity may affect the lungs, liver, and bone marrow. Methotrexate can cause pneumonitis that can become life threatening. Symptoms typically include progressive shortness of breath, cough, and fever. Hypoxemia and tachypnea are always present, and chest radiograph often reveals a diffuse interstitial or mixed interstitial and alveolar infiltrate, commonly in the lower lung fields. Pulmonary function tests show a restrictive pattern with diffusion abnormalities ([15]).

Azathioprine and 6-mercaptopurine: Immunomodulatory drugs, such as azathioprine (AZA) and 6-mercaptopurine (6-MP) can potentiate the therapeutic effect of glucocorticoids and exert a glucocorticoid-sparing effect in patients with glucocorticoid-dependent ulcerative colitis. Drug-induced hypersensitivity pneumonitis is a rare but potentially serious complication of therapy with these agents. Other pathologic patterns, such as usual interstitial pneumonia and bronchiolitis obliterans with organizing pneumonia, have rarely been reported in patients with inflammatory bowel disease treated with AZA or 6-MP ([57]). Infliximab: Infliximab, an inhibitor of tumor necrosis factor-alpha, is used in selected patients with Crohn's disease, particularly those with fistulizing disease. Infectious complications from use of infliximab are well-described, most notably in the development of tuberculosis ([58]). There are also case reports of interstitial pneumonitis developing in patients with rheumatoid arthritis and Crohn's disease treated with infliximab (Figure 4) ([59]).

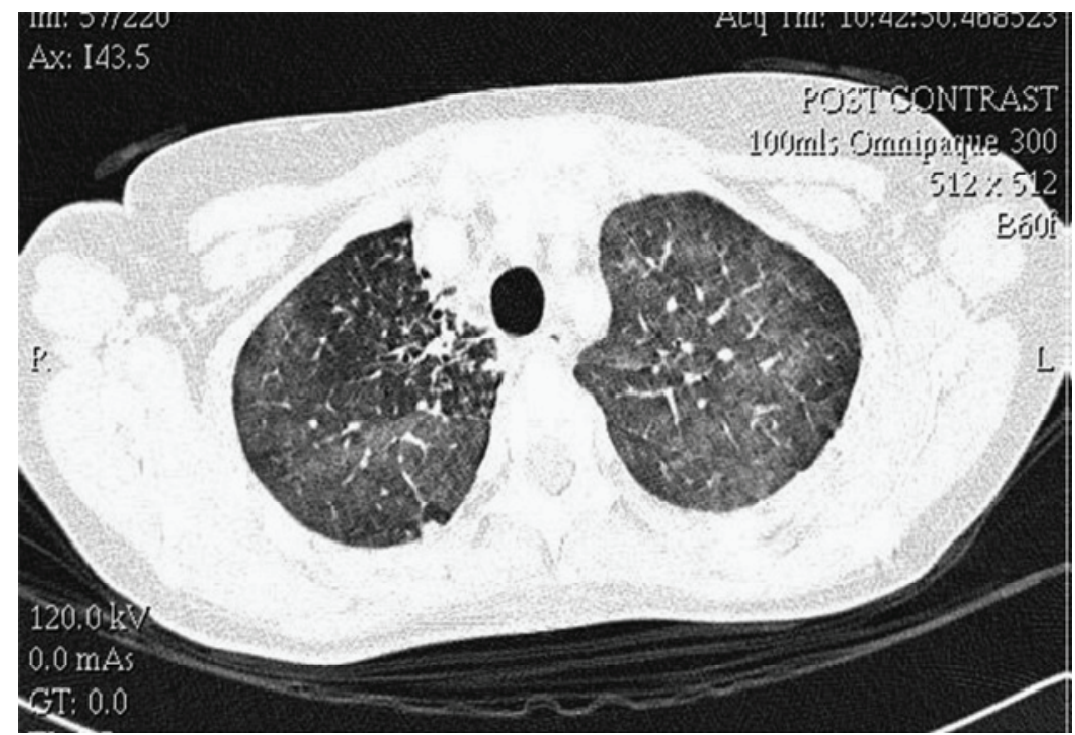

Fig. 4. High-resolution computed tomography of the thorax revealed extensive ground glass shadowing with right apical peribronchial consolidation ([59]) 


\section{Diagnosis and treatment}

The first step in determining appropriate therapy is to consider the possible role of druginduced disease and the possibility of superimposed bacterial infection. When patients with inflammatory bowel disease who are treated with sulfasalazine or 5-ASA develop pulmonary infiltrates with eosinophilia, it is reasonable to assume initially that druginduced disease is present and to discontinue the drug ([12]). The possible role of drug toxicity is less clear with other clinical presentations of parenchymal lung disease, such as interstitial disease or bronchiolitis obliterans with organizing pneumonia. In this setting, any decision concerning cessation of drug therapy should consider the relative severity of the pulmonary disease and the inflammatory bowel disease, which could flare if the drug is withdrawn. Possible superimposed bacterial or mycobacterial infection should be excluded in patients with fever, cough, or purulent sputum production. Appropriate antimicrobial therapy should be given if infection is found. Prophylaxis against venous thromboembolism (VTE) should be considered in hospitalized patients without evidence of gastrointestinal bleeding or other contraindications, since the risk of VTE may be increased in patients with inflammatory bowel disease $([47,49$, $52,60,61])$.

Antiinflammatory drugs: For those patients in whom neither drug therapy nor infection seems to be playing a role, inhaled or systemic glucocorticoids may be effective, depending upon the type of pulmonary complication. Inhaled glucocorticoid therapy, often in relatively high doses (eg, beclomethasone $1500-2000 \mathrm{mcg} /$ day), is frequently effective in the various forms of airway inflammation. Large airway inflammation tends to be more responsive than bronchiolitis, presumably due to relatively poor delivery of the inhaled medication to the affected small airways. Patients with copious sputum production (greater than $50 \mathrm{~mL} /$ day) and those with bronchiectasis are also less likely to respond to inhaled glucocorticoids and may require oral glucocorticoids. Potentially life-threatening airway inflammation, as with subglottic involvement causing upper airway obstruction, may require intravenous glucocorticoids. The pulmonary parenchymal complications of inflammatory bowel disease require oral glucocorticoid therapy; we usually use prednisone at an initial dose of 0.5 to $1.0 \mathrm{mg} / \mathrm{kg}$ per day. Most patients have a good response to glucocorticoid therapy. The duration of treatment has not been well established, but is likely to be a number of months ([2]).

Serositis in the form of pleural effusions may need therapy if the effusions produce symptoms. Nonsteroidal antiinflammatory therapy should be tried initially, but glucocorticoids may be necessary if the patient does not respond. A single case of cardiac tamponade requiring pericardial drainage has been reported ([17]). There is insufficient evidence to support the use of infliximab or other agents directed against tumor necrosis factor in the management of pulmonary disease associated with IBD.

In conclusion, although most patients have subclinical disease, the pulmonologist must be aware of the multiple potential pulmonary manifestations that can occur in a patient with IBD. To get over this problem a complex work-up is needed ( Table 1. Based on Storch Et al. [15]). Otherwise, they tend to generate persistent and annoying symptoms, and can lead to destructive and irreversible changes in the airway wall, or the "end-stage lung" ([12]). 


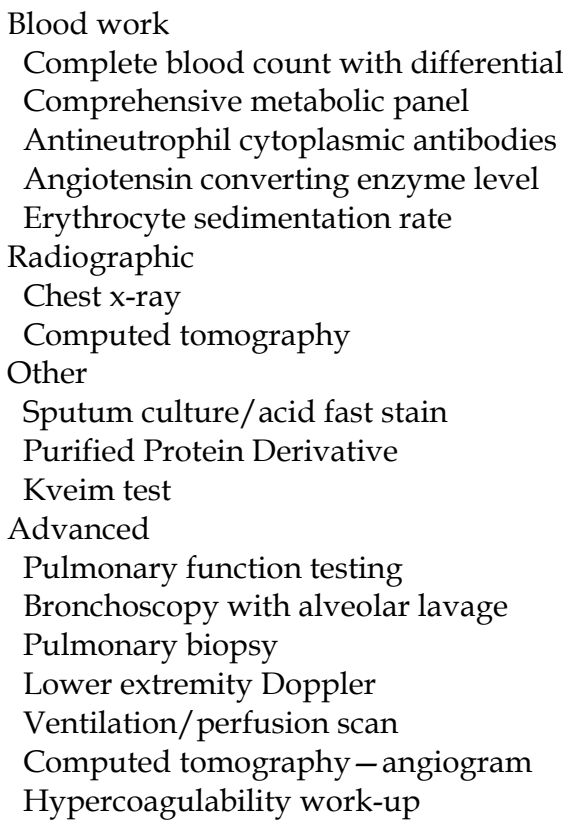

Table 1. Work-up of pulmonary disease in IBD

\section{References}

[1] Loftus EV Jr. Clinical epidemiology of inflammatory bowel disease: Incidence, prevalence, and environmental influences. Gastroenterology 2004; 126:1504.

[2] http://www.uptodate.com/contents/pulmonary-complications-of-inflammatorybowel-disease (accessed June 2, 2011).

[3] Shivananda S, Lennard-Jones J, Logan R, et al. Incidence of inflammatory bowel disease across Europe: is there a difference between north and south? Results of the European Collaborative Study on Inflammatory Bowel Disease (EC-IBD). Gut 1996; 39:690.

[4] Trallori G, Palli D, Saieva C, et al. A population-based study of inflammatory bowel disease in Florence over 15 years (1978-92). Scand J Gastroenterol 1996; 31:892.

[5] Boyko EJ, Koepsell TD, Perera DR, Inui TS. Risk of ulcerative colitis among former and current cigarette smokers. N Engl J Med 1987; 316:707.

[6] Logan RF, Edmond M, Somerville KW, Langman MJ. Smoking and ulcerative colitis. Br Med J (Clin Res Ed) 1984; 288:751.

[7] Harries AD, Baird A, Rhodes J. Non-smoking: a feature of ulcerative colitis. Br Med J (Clin Res Ed) 1982; 284:706.

[8] Tobin MV, Logan RF, Langman MJ, et al. Cigarette smoking and inflammatory bowel disease. Gastroenterology 1987; 93:316. 
[9] Vessey M, Jewell D, Smith A, et al. Chronic inflammatory bowel disease, cigarette smoking, and use of oral contraceptives: findings in a large cohort study of women of childbearing age. Br Med J (Clin Res Ed) 1986; 292:1101.

[10] Mahid SS, Minor KS, Soto RE, et al. Smoking and inflammatory bowel disease: a metaanalysis. Mayo Clin Proc 2006; 81:1462.

[11] Yilmaz A, Yilmaz Demirci N, Hoşgün D, Uner E, Erdoğan Y, Gökçek A, Cağlar A. Pulmonary involvement in inflammatory bowel disease. World J Gastroenterol. 2010 Oct 21; 16(39):4952-7.

[12] Camus P, Piard F, Ashcroft T, et al. The lung in inflammatory bowel disease. Medicine (Baltimore) 1993; 72:151.

[13] Casey MB, Tazelaar HD, Myers JL, et al. Noninfectious lung pathology in patients with Crohn's disease. Am J Surg Pathol 2003; 27: 213.

[14] Parry SD, Barbatzas C, Peel ET, Barton JR. Sulphasalazine and lung toxicity. Eur Respir J 2002; 19:756.

[15] Storch I, Sachar D, Katz S. Pulmonary manifestations of inflammatory bowel disease. Inflamm Bowel Dis 2003; 9:104-115.

[16] Kuzela L, Vavrecka A, Prikazska M, et al. Pulmonary complications in patients with inflammatory bowel disease. Hepatogastroenterology 1999; 46:1714.

[17] Black H, Mendoza M, Murin S. Thoracic manifestations of inflammatory bowel disease. Chest 2007; 131:524.

[18] Douglas JG, McDonald CF, Leslie MJ, et al. Respiratory impairment in inflammatory bowel disease: does it vary with disease activity? Respir Med 1989; 83:389-394.

[19] Songur N, Songur Y, Tuzun M, et al. Pulmonary function tests and high-resolution CT in the detection of pulmonary involvement in inflammatory bowel disease. J Clin Gastroenterol 2003; 37:292-298.

[20] Ceyhan BB, Karakurt S, Cevik H, et al. Bronchial hyperreactivity and allergic status in inflammatory bowel disease. Respiration 2003; 70:60-66.

[21] Mahadeva R, Walsh G, Flower CD, Shneerson JM. Clinical and radiological characteristics of lung disease in inflammatory bowel disease. Eur Respir J 2000; 15: 41-48.

[22] Tzanakis $N$, Bouros $D$, Samiou $M$, et al. Lung function in patients with inflammatory bowel disease. Respir Med 1998; 92: 516-522.

[23] Tzanakis N, Samiou M, Bouros D, et al. Small airways function in patients with inflammatory bowel disease. Am J Respir Crit Care Med 1998; 157:382-386.

[24] Marvisi M, Borrello PD, Brianti M, et al. Changes in the carbon monoxide diffusing capacity of the lung in ulcerative colitis. Eur Respir J 2000; 16:965-968.

[25] Pasquis P, Colin R, Denis P, et al. Transient pulmonary impairment during attacks of Crohn's disease. Respiration 1981; 41:56-59.

[26] Mansi A, Cucchiara S, Greco L, et al. Bronchial hyperresponsiveness in children and adolescents with Crohn's disease. Am J Respir Crit Care Med 2000; 161:1051-1054.

[27] Louis E, Louis R, Drion V, et al. Increased frequency of bronchial hyperresponsiveness in patients with inflammatory bowel disease. Allergy 1995; 50:729-733.

[28] Louis E, Louis R, Shute J, et al. Bronchial eosinophilic infiltration in Crohn's disease in the absence of pulmonary disease. Clin Exp Allergy 1999; 29:660-666. 
[29] Koek GH, Verleden GM, Evenepoel P, Rutgeerts P. Activity related increase of exhaled nitric oxide in Crohn's disease and ulcerative colitis: a manifestation of systemic involvement? Respir Med. 2002; 96: 530-5.

[30] Ozyilmaz E, Yildirim B, Erbas G, Akten S, Oguzulgen IK, Tunc B, Tuncer C, Turktas H. Value of fractional exhaled nitric oxide (FE NO) for the diagnosis of pulmonary involvement due to inflammatory bowel disease. Inflamm Bowel Dis. 2010 Apr;16(4):670-6.

[31] Higenbottam T, Cochrane GM, Clark TJ, et al. Bronchial disease in ulcerative colitis . Thorax 1980; 35:581.

[32] Kuźniar T, Sleiman C, Brugière $\mathrm{O}$, et al. Severe tracheobronchial stenosis in a patient with Crohn's disease. Eur Respir J 2000; 15:209.

[33] Mansi A, Cucchiara S, Greco L, et al. Bronchial hyperresponsiveness in children and adolescents with Crohn's disease. Am J Respir Crit Care Med 2000; 161:1051.

[34] Garg K, Lynch DA, Newell JD. Inflammatory airways disease in ulcerative colitis: CT and high-resolution CT features. J Thorac Imaging 1993; 8:159.

[35] Spira A, Grossman R, Balter M. Large airway disease associated with inflammatory bowel disease. Chest 1998; 113:1723.

[36] Vandenplas O, Casel S, Delos M, et al. Granulomatous bronchiolitis associated with Crohn's disease. Am J Respir Crit Care Med 1998; 158:1676.

[37] Barr GD, Shale DJ, Jewell DP. Ulcerative colitis and sarcoidosis. Postgrad Med J 1986; 62: 341-345.

[38] Papadopoulos KI, Hornblad Y, Liljebladh H, et al. High frequency of endocrine autoimmunity in patients with sarcoidosis. Eur J Endocrinol 1996; 134:331-336.

[39] Storch I, Rosoff L, Katz S. Sarcoidosis and inflammatory bowel disease. J Clin Gastroenterol 2001; 33:345.

[40] Smiejan JM, Cosnes J, Chollet-Martin S, et al. Sarcoid-likelymphocytosis of the lower respiratory tract in patients with active Crohn's disease. Ann Intern Med 1986; 104:17-21.

[41] Bernstein CN, Wajda A, Blanchard JF. The clustering of other chronic inflammatory diseases in inflammatory bowel disease: a population-based study. Gastroenterology 2005; 129:827-836.

[42] Yang P, Tremaine WJ, Meyer RL, et al. $a_{1}$-Antitrypsin deficiency and inflammatory bowel diseases. Mayo Clin Proc 2000; 75: 450-455.

[43] Kasuga I, Yanagisawa N, Takeo C, et al. Multiple pulmonary nodules in association with pyoderma gangrenosum. Respir Med 1997; 91: 493.

[44] Swinburn CR, Jackson GJ, Cobden I, et al. Bronchiolitis obliterans organising pneumonia in a patient with ulcerative colitis. Thorax 1988; 43:735-736.

[45] W. Sloan, A. Bargen and R. Gage, Life histories of patients with chronic ulcerative colitis: a review of 2000 cases, Gastroenterology (1950), pp. 25-38.

[46] C.N. Bernstein, J.F. Blanchard and D.S. Houston et al., The incidence of deep venous thrombosis and pulmonary embolism among patients with inflammatory bowel disease: a population-based cohort study, Thromb Haemost (2001), pp. 430-434.

[47] W. Miehsler, W. Reinisch and E. Valic et al., Is inflammatory bowel disease an independent and disease specific risk factor for thromboembolism?, Gut (2004), pp. 542-548. 
[48] Talbot RW, Heppell J, Dozois RR, et al. Vascular complications of inflammatory bowel disease. Mayo Clin Proc 1986; 61:140 -145.

[49] Quera R, Shanahan F. Thromboembolism: an important manifestation of inflammatory bowel disease. Am J Gastroenterol 2004; 99:1971-1973.

[50] Papa A, Danese S, Grillo A, et al. Review article: inherited thrombophilia in inflammatory bowel disease. Am J Gastroenterol2003; 98:1247-1251.

[51] Oldenburg B, Fijnheer R, van der Griend R, et al. Homocysteine in inflammatory bowel disease: a risk factor for thromboembolic complications? Am J Gastroenterol 2000; 95:2825-2830.

[52] C.A. Solem, E.V. Loftus and W.J. Tremaine et al., Venous thromboembolism in inflammatory bowel disease, Am J Gastroenterol (2004), pp. 97-101.

[53] Tanigawa K, Sugiyama K, Matsuyama H, et al. Mesalazine-induced eosinophilic pneumonia. Respiration 1999; 66:69.

[54] Bitton A, Peppercorn MA, Hanrahan JP, Upton MP. Mesalamine-induced lung toxicity. Am J Gastroenterol 1996; 91:1039.

[55] Hamadeh MA, Atkinson J, Smith LJ. Sulfasalazine-induced pulmonary disease. Chest 1992; 101:1033.

[56] Salerno SM, Ormseth EJ, Roth BJ, et al. Sulfasalazine pulmonary toxicity in ulcerative colitis mimicking clinical features of Wegener's granulomatosis. Chest 1996; 110:556.

[57] Ananthakrishnan AN, Attila T, Otterson MF, et al. Severe pulmonary toxicity after azathioprine/6-mercaptopurine initiation for the treatment of inflammatory bowel disease. J Clin Gastroenterol 2007; 41:682.

[58] Keane J, Gershon S, Wise RP, et al. Tuberculosis associated with infliximab, a tumor necrosis factor alpha-neutralizing agent. N Engl J Med 2001; 345:1098.

[59] Weatherhead M, Masson S, Bourke SJ, et al. Interstitial pneumonitis after infliximab therapy for Crohn's disease. Inflamm Bowel Dis 2006; 12:427.

[60] Bonderman D, Jakowitsch J, Adlbrecht C, et al. Medical conditions increasing the risk of chronic thromboembolic pulmonary hypertension. Thromb Haemost 2005; 93:512.

[61] Sonoda K, Ikeda S, Mizuta Y, et al. Evaluation of venous thromboembolism and coagulation-fibrinolysis markers in Japanese patients with inflammatory bowel disease. J Gastroenterol 2004; 39:948. 


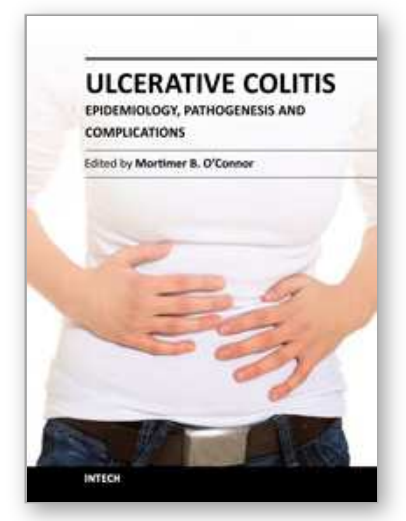

\author{
Ulcerative Colitis - Epidemiology, Pathogenesis and Complications \\ Edited by Dr Mortimer O'Connor
}

ISBN 978-953-307-880-9

Hard cover, 280 pages

Publisher InTech

Published online 14, December, 2011

Published in print edition December, 2011

This book is intended to act as an up-to-date reference point and knowledge developer for all readers interested in the area of gastroenterology and in particular, Ulcerative Colitis. All authors of the chapters are experts in their fields of publication, and deserve individual credit and praise for their contributions to the world of Ulcerative Colitis. We hope that you will find this publication informative, stimulating, and a reference point for the area of Ulcerative colitis as we move forward in our understanding of the field of medicine.

\title{
How to reference
}

In order to correctly reference this scholarly work, feel free to copy and paste the following:

Nilgün Yılmaz Demirci (2011). Ulcerative Colitis and Lung, Ulcerative Colitis - Epidemiology, Pathogenesis and Complications, Dr Mortimer O'Connor (Ed.), ISBN: 978-953-307-880-9, InTech, Available from:

http://www.intechopen.com/books/ulcerative-colitis-epidemiology-pathogenesis-and-complications/ulcerativecolitis-and-lung

\section{INTECH}

open science | open minds

\section{InTech Europe}

University Campus STeP Ri

Slavka Krautzeka 83/A

51000 Rijeka, Croatia

Phone: +385 (51) 770447

Fax: +385 (51) 686166

www.intechopen.com

\section{InTech China}

Unit 405, Office Block, Hotel Equatorial Shanghai

No.65, Yan An Road (West), Shanghai, 200040, China

中国上海市延安西路65号上海国际贵都大饭店办公楼 405 单元

Phone: +86-21-62489820

Fax: $+86-21-62489821$ 
(C) 2011 The Author(s). Licensee IntechOpen. This is an open access article distributed under the terms of the Creative Commons Attribution 3.0 License, which permits unrestricted use, distribution, and reproduction in any medium, provided the original work is properly cited. 